\title{
Airport passenger experiences in concourses with either electrochromic or low-e glass windows
}

\author{
Alan Hedge* \\ Department Design + Environmental Analysis, \\ Cornell University, \\ Ithaca, NY 14853, USA \\ Email: ah29@cornell.edu \\ *Corresponding author

\section{Piers MacNaughton, May Woo, Robert Guglielmetti and Brandon Tinianov}

\author{
View Inc., \\ 195 S. Milpitas Blvd, \\ Milpitas, CA 95035, USA \\ Email: piers.macnaughton@view.com \\ Email: may.woo@view.com \\ Email: robert.guglielmetti@view.com \\ Email: brandon.tinianov@view.com
}

\begin{abstract}
A survey of travellers was conducted at a major US airport. A computer-based questionnaire was administered during the daytime to 573 passengers at their departure gate seating areas in either a concourse with low-emissivity glass or a newly constructed concourse with electrochromic glass. Sample sizes and characteristics were comparable for respondents in the two concourses. In the concourse with electrochromic glass, window surface temperatures were significantly cooler and more spatially consistent, and passenger comfort with daylight and positive mood were significantly better; respondents were $68 \%$ more likely to report being very satisfied with their gate experience. Overall, results agree with previous research showing that the visual environment and visual experience for airline passengers is improved by using electrochromic glass at airport gates.
\end{abstract}

Keywords: electrochromic glass; low-e glass; airports; daylight; user experience; user mood; passenger satisfaction.

Reference to this paper should be made as follows: Hedge, A., MacNaughton, P., Woo, M., Guglielmetti, R. and Tinianov, B. (2021) 'Airport passenger experiences in concourses with either electrochromic or low-e glass windows', Int. J. Aviation Management, Vol. 5, No. 1, pp.1-16.

Biographical notes: Alan Hedge is a Professor Emeritus in the Design and Environmental Analysis Department at Cornell University. For over four decades he has conducted research on environmental and ergonomic design studies and taught on these topics. He has a BS and MS in Zoology and an MS and $\mathrm{PhD}$ in Applied Psychology. He is extensively published with four books and over 250 articles. He has received several awards for his work. He is a 
Fellow of several ergonomics societies and a Certified and Chartered Professional Ergonomist. Currently, he is President of Humanuse, an ergonomics consulting company.

Piers MacNaughton is the Director of Health Strategy at View Inc. and a Research Associate at the Harvard T.H. Chan School of Public Health. He graduated from Tufts University with a degree in environmental engineering and subsequently from the Harvard T.H. Chan School of Public Health with a Master of Science and Doctor of Science in Exposure, Epidemiology and Risk in the Department of Environmental Health.

May Woo is the Manager of Health Strategy at View Inc., where she conducts research investigating the impact of sustainable technologies and practices in the built environment on the health and wellness of the people who occupy those buildings. Her interdisciplinary research background lies at the intersection of the environment, both indoor and outdoor, and human health. She graduated from Harvard T.H. Chan School of Public Health with a Master of Science in Environmental Health and from Tufts University with a Bachelor of Science in Biology.

Robert Guglielmetti is a Senior Lighting Specialist at View. His areas of expertise are daylighting, physically based lighting simulation, the integration of lighting simulation with whole-building energy simulations, and high dynamic range imaging. He has more than 25 years' experience in applying these talents toward healthy, energy-efficient, and delightful built environments. He is an advisory member of the Illuminating Engineering Society of North America's Daylight Metrics Committee, and served on the board of directors of the International Building Performance Simulation Association, and the International Lighting Commission's Technical Committee on Climate-based Daylight Modeling.

Brandon Tinianov currently serves as the View's VP of Industry Strategy where he leads their value-based product strategy and industry engagement. Prior to joining View, Brandon was the Chief Technology Officer at Serious Energy for seven years. He has managed multiple nationally accredited labs including laboratories for acoustic, fire-testing, heat transfer, and physical properties. He is a member of the national Advisory Council of the US Green Building Council. He has a PhD in Engineering Systems from the Colorado School of Mines and is a registered Professional Engineer and LEED Accredited Professional. He has 28 issued patents.

\section{Introduction}

Airline travel constitutes a significant portion of the United States economy. In 2016, the US Department of Transportation reported that aviation accounted for more than $5 \%$ of the Gross Domestic Product, contributing \$1.6 trillion in total economic activity and supporting nearly 11 million jobs that year (USDOT, 2019). Each month in 2019, nearly 80 million travellers were in transit in US airports and the number of travellers continues to increase by $2.5 \%$ annually (USDOT, 2020). However, in 2019, traveller satisfaction rankings with airports and the aviation industry were down throughout the country (Johnson, 2019). To improve satisfaction scores and minimise the stress of airline travel, many US airports are investing in upgrading their facilities to provide travellers with a 
more pleasant travel experience. This will involve upgrading many of the more than 19,000 airports across the country that are, on average, 40 years old. In the next three years, more than 50 airports in the US will have renovation projects totalling some $\$ 70$ billion in construction (Nabers, 2019; Martin, 2019). One such airport under renovation is Charlotte Douglas International Airport (CLT), a Cat X hub that had 46.4 million passengers in 2018 and ranked $10^{\text {th }}$ in passenger satisfaction in 2019 (Power, 2019). CLT has a ten-year, $\$ 2.5$ billion set of renovation and expansion projects dubbed 'destination CLT' underway, which included a 213,000 square foot Concourse A Expansion in 2018 - a project that added nine new airline gates.

Although it is assumed that these renovations will improve the passenger experience, there has been little systematic behavioural research to date that has quantitatively studied these effects. Those that have been conducted show that the physical airport environment - that is, conditions such as lighting and temperature - plays a crucial role in passenger comfort, a benefit that extends beyond the passenger and increases the commercial performance of the airport. In one study of 346 passengers at a Dutch international airport, improving the lighting at the departure and arrival gates was an important stress-reducing feature that provided passengers with a more comfortable experience (Van Oel and van den Berkhof, 2013). In another study at three terminals in the United Kingdom, passenger-perceived thermal conditions were associated with their overall comfort levels, with a dominant preference for cooler temperature conditions (Kotopouleas and Nikolopoulou, 2018). In yet another study in eight major Chinese airports, measured indoor environmental factors were found to be highly correlated to passenger satisfaction (Geng et al., 2017). Research also demonstrates that people's nervousness, anxiety and stress levels are reduced when looking through windows with an outdoor view (Adey, 2008).

Designing the airport environment for passenger comfort can also lead to commercial performance benefits; Adey (2008) found that airport design features that reduce passenger stress can increase retail revenue, and $\mathrm{Wu}$ and Chen (2019) found that longer dwell time can impact spending by increasing retail engagement. In a comparative survey of passenger experience in the Dallas Fort Worth International Airport conducted at two gates, one with conventional façade glass and one with electrochromic glass, results showed that passenger satisfaction levels were significantly higher, gate dwell time was longer, and retail revenue was higher in the gate with the electrochromic glass (Hedge and Nou, 2018).

Beyond transmitting visible light into a space, use of traditional low-emissivity (low-e) glass on window façades also allows entrance of infrared wavelengths and glare, which warms the interior space and can cause visual discomfort, respectively. Deploying external or internal blinds on windows can reduce solar gain but also reduces visible light levels and obstructs an exterior view. Electrochromic glass is a technology that allows for the digital control of the light transmittance of glass by changing its tint state (Sibilio et al., 2016). Electrochromic glass can filter out infrared wavelengths in sunlight that would otherwise heat the interior space, reduce the glare from the sun, yet still allow a view to the exterior (Hedge et al., 2018). At CLT, the electrochromic glass varies between three tint states ranging from 58\% visible light transmittance (Tvis) comparable to typical low-e glass - and down to 6\% Tvis. An algorithm factoring in the sun's position in the sky, the façade orientation, and real-time cloud cover information determines the tint state of the glass at any given time. 
The present study at CLT compared passenger experience and comfort in a newly constructed concourse fitted with electrochromic glass to those for passengers in another concourse with conventional low-e glass. It was hypothesised that passengers will experience greater visual comfort with daylight in the concourse with the electrochromic glass, translating to improvements in overall satisfaction with the gate experience.

\section{Methods}

\subsection{Study site}

This research was conducted in two concourses at CLT. One concourse was constructed with electrochromic glass (Concourse A Expansion) and the other concourse was located in an existing area of the airport fitted with conventional façade glass (Concourse E). Figure 1 shows the airport layout for each of the survey sites. The concourses and survey gates selected had similar South-facing façade orientations, allowing for a comparison of passenger reactions in the terminals under equivalent outdoor solar exposure during the study.

Figure 1 The airport concourses surveyed (see online version for colours)

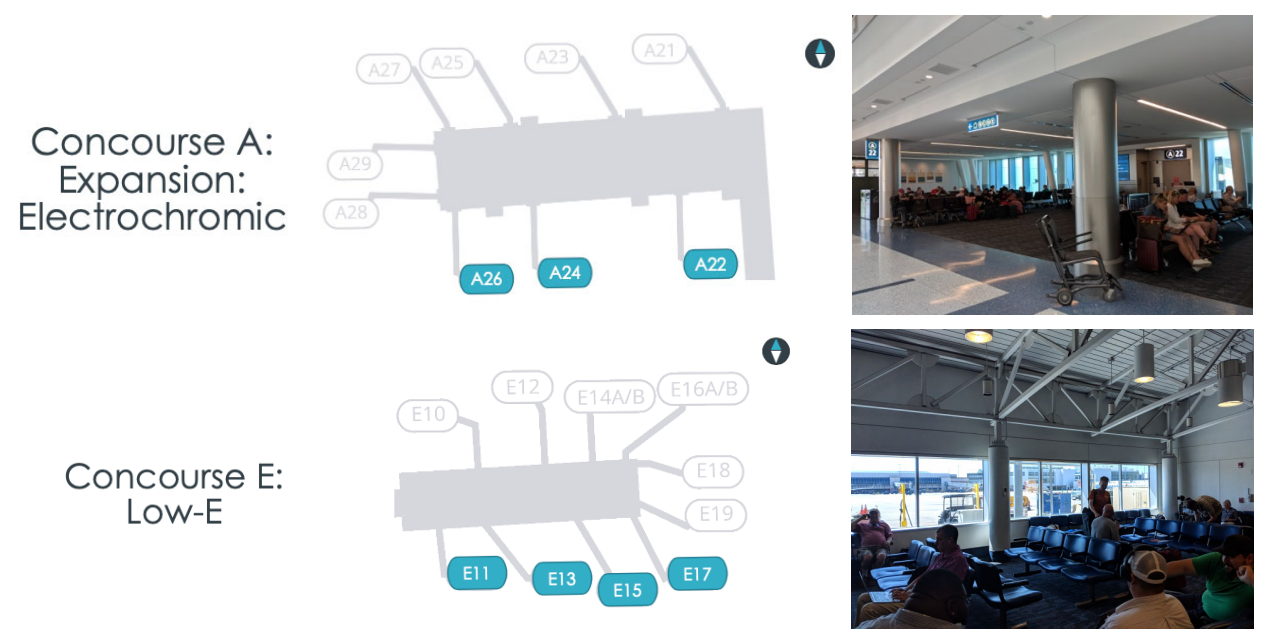

Note: Passengers were surveyed in the highlighted gates on the south side of each concourse.

Two of the gates (A24; A26) in the Concourse A Expansion had 8.5 metres floor-to-ceiling glass windows, and one gate (A22) had 3 metres floor-to-ceiling glass windows. Gates in Concourse E had 1.8 metres windows with conventional façade glass (Figure 1). The seating arrangements in the two concourses were similar with seating primarily aligned perpendicular to the façade. As Concourse A expansion was wider than Concourse E, the seating extended further back from the windows, resulting in $27 \%$ of respondents having been seated within 3 metres of the windows in the Concourse A expansion compared to $42 \%$ in Concourse E. In addition to changes in the façade, Concourse A expansion had modern interior furnishing, finishes and amenities. 


\subsection{Environmental monitoring}

Light measurements were obtained using high dynamic range (HDR) imagery. A Canon EOS-R full frame camera and $8 \mathrm{~mm}$ hemispherical fisheye lens, capable of capturing a full 180-degree hemisphere, were used in conjunction with a microcomputer (RasberryPi) to take a full range of 1/3-stop bracketed exposures, at each location and timestep. Luminance (photosphere) and radiance (hdrgen) software were used for conversion of the bracketed exposures to HDR images for the analysis. Images were captured at approximately 10:15 am and 12:00 pm on 23 September 2019 at Gate A24 in the electrochromic concourse and at Gate E11 at the control concourse. HDR imagery measures luminance levels, from which daylight glare probability (DGP) as a metric of visual comfort was evaluated. DGP predicts daylight discomfort glare as a function of vertical eye illuminance, glare source luminance and glare source position in the visual field and has been shown to strongly correlate with user perceptions of glare (Wienold and Christoffersen, 2007). Capturing the images at consistent times of day and on facades with the same orientation allowed for accurate comparison of lighting conditions across the two concourses.

Window surface temperatures were also measured in the afternoon on 23 September 2019 at the same locations as the HDR imagery using a Forward-Looking Infrared Radar thermal imaging camera that senses infrared radiation (FLIR ONE Pro).

\subsection{Survey sample}

A total of 573 passengers completed a computer-administered questionnaire asking about their experiences in their current concourse: 290 responses were from the concourse A with electrochromic glass and 283 were from the concourse E with conventional low-e glass.

\subsection{Survey questionnaire}

A survey questionnaire was developed building on previous research surveys (Hedge et al., 2018; Wienold and Christoffersen, 2007). The questionnaire evaluated passenger demographics, comfort and satisfaction with daylight conditions, impacts of daylight on passenger activities, preferences for airport amenities, and passenger experience more generally. The survey also included a modified Kansei scale for respondents to rate their mood on a set of positive descriptors (modern, efficient, comfortable, relaxed, excited, energised, awake, bright) and negative descriptors (out-dated, ineffective, miserable, tense, annoyed, fatigued, tired and dark).

\subsection{Survey procedure}

All respondents were asked to complete an electronic survey administered using an iPad. All surveys were conducted between the hours of 9 am to $5 \mathrm{pm}$ over the course of six days with clear weather in September: 15, 18, 19, 20, 23, 24, and 29/2019. On each day, the interviewer administered surveys in one concourse from 9 am to $1 \mathrm{pm}$ and then switched to the other concourse from $1 \mathrm{pm}$ to $5 \mathrm{pm}$. The interviewer alternated which concourse would be sampled first to balance the number of responses in each concourse by time of day. All surveys were administered by experienced independent researchers 
(Phoenix Marketing International). Incomplete responses were removed from the analysis.

\section{Results}

\subsection{Sample demographics}

There was no significant difference in the distribution of gender in each sample (chi-square test, $\chi^{2}=1.446, \mathrm{df}=1, \mathrm{p}=0.229$ : see Table 1 ). There was no statistically significant difference (student's t-test, $\mathrm{t}=-0.281 \mathrm{df}=507, \mathrm{p}=0.779$ ) in dwell time in each concourse (electrochromic $=39.9$ minutes; control $=40.9$ minutes), indicating that dwell time was unlikely to be a confounder in passenger responses.

Table 1 Summary of the sample characteristics

\begin{tabular}{lcccc}
\hline \multirow{2}{*}{\begin{tabular}{l}
\multirow{2}{*}{ Respondents by glass type } \\
\cline { 2 - 4 }
\end{tabular}} & Female & Male & \multirow{2}{*}{ Total } \\
\cline { 3 - 4 } Electrochromic & Count & 157 & 133 & 290 \\
glass & \% within concourse & $54.1 \%$ & $45.9 \%$ & $100.0 \%$ \\
Control & Count & 139 & 144 & 283 \\
(low-e glass) & \% within concourse & $49.1 \%$ & $50.9 \%$ & $100.0 \%$ \\
Total & Count & 296 & 277 & 573 \\
& $\%$ within concourse & $51.7 \%$ & $48.3 \%$ & $100.0 \%$ \\
\hline
\end{tabular}

\subsection{Pre-interview activities}

There was no significant difference (chi-square test, $\chi^{2}=13.606, \mathrm{df}=15, \mathrm{p}=0.556$ ) in the immediate pre-interview activities of respondents in the study. Patterns of pre-interview activities for respondents were comparable in each concourse (see Table 2).

Table 2 Pre-interview passenger activity

\begin{tabular}{lcc}
\hline \multirow{2}{*}{ Activity prior to interview } & \multicolumn{2}{c}{ Respondents by glass type } \\
\cline { 2 - 3 } & Electrochromic & Control \\
\hline Eating & 12 & 19 \\
Eating; using a phone & 6 & 4 \\
Eating; using a tablet & 0 & 1 \\
None & 43 & 38 \\
Other & 15 & 14 \\
Reading a physical newspaper/magazine/book & 23 & 17 \\
Using a computer & 36 & 18 \\
Using a phone & 136 & 150 \\
Using a phone; reading a physical newspaper/magazine/book & 1 & 0 \\
Using a phone; using a computer & 3 & 1 \\
Using a phone; using a tablet & 1 & 2 \\
Using a tablet & 13 & 20 \\
\hline
\end{tabular}




\subsection{Window tint state}

For the gates in the concourse with electrochromic glass, the tint state of the gate's window façade when the survey was collected ranged from 1 (clearest tint) to 3 (darkest tint). Because surveys were collected near the south façade during daylight hours on sunny days, the glass proximal to the respondent was in its darkest tint state (Tvis $=6 \%$ ) for $91 \%$ of the responses in the Concourse A Expansion.

\subsection{Gate temperature}

Spot measurement of the window surface temperatures on the same day and time using an infrared camera (FLIR imagery) detected an approximately $9^{\circ} \mathrm{C}$ cooler temperature at a gate within the concourse with electrochromic glass compared to a gate within the concourse with conventional glass. Figure 2 shows the FLIR images with the temperature readings at Gates E11 and A24 respectively.

Figure 2 Forward-Looking Infrared Radar (FLIR) images at two different concourses,

(a) concourse with conventional low-e glass (b) concourse with electrochromic glass (see online version for colours)

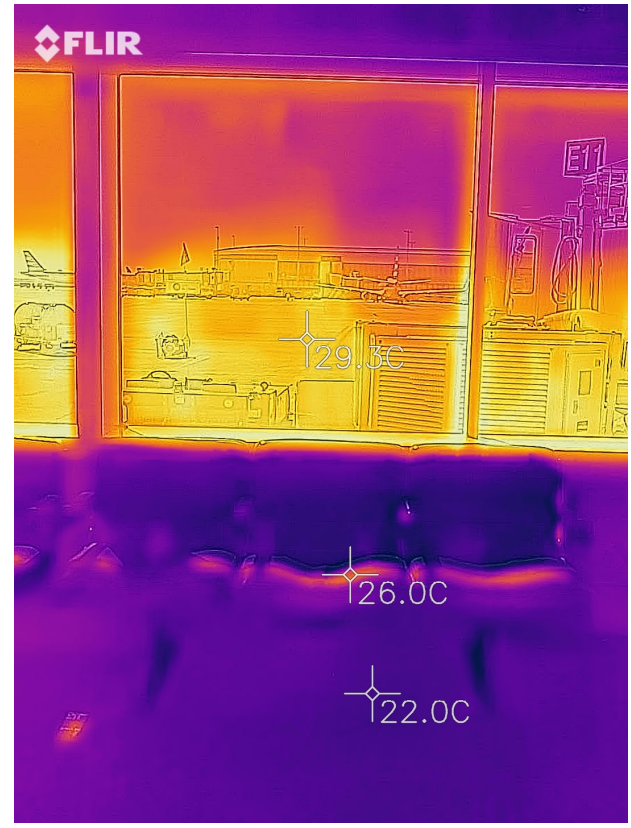

(a)

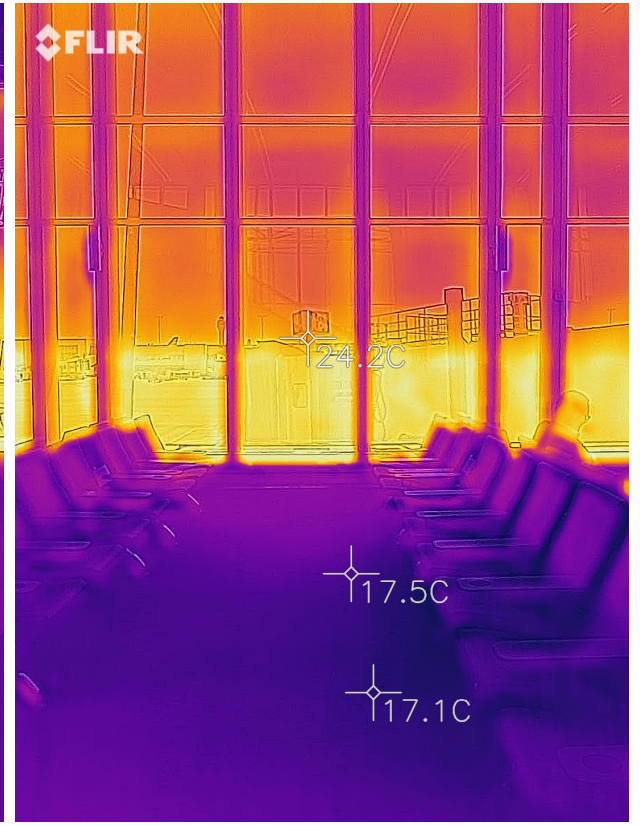

(b)

\subsection{Daylight comfort at the gate}

Across different times of day, daylight glare probability as quantified from the HDR imagery was lower in the concourse with electrochromic glass compared to the concourse with conventional low-e glass. Figure 3 shows the HDR images and DGP values side by side at two different times. The DGP metric is largely based upon subjective testing in 
office environments where subjects were asked to report comfort and ease of task performance under various daylit conditions. There is consensus in the lighting industry that a DGP $<0.35$ indicates general satisfaction with the luminous environment, i.e. a minimal number of persons would be disturbed by glare from such a view position. Both the electrochromic and control gates in this study reported DGP below 0.35 due to the solar angles present at the time of the study as well as favourable shielding from the building architecture itself.

Figure 3 HDR images and associated daylight glare probability (DGP) values at the two different concourses at different times of day (see online version for colours)

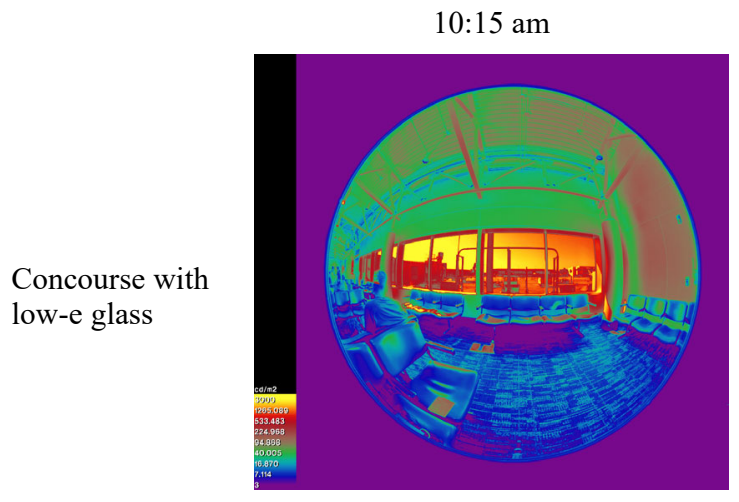

DGP: 0.27

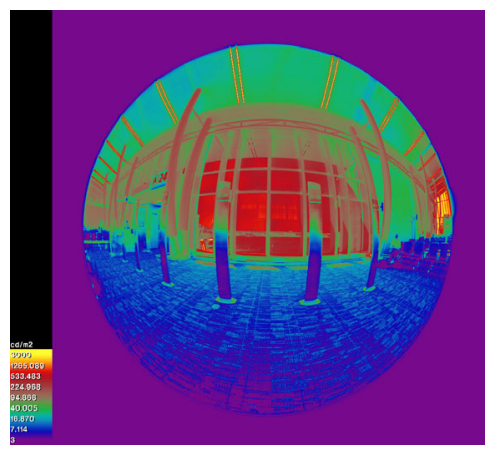

DGP: 0.18

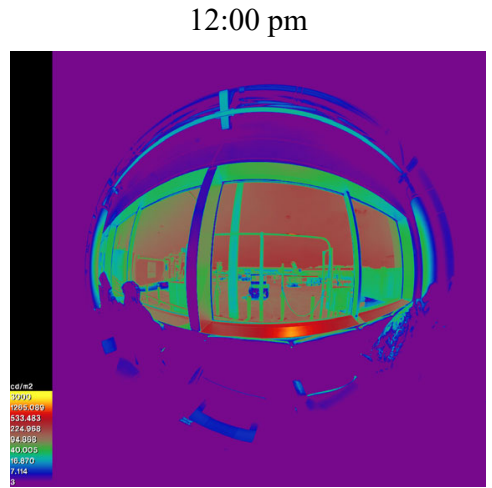

DGP: 0.13

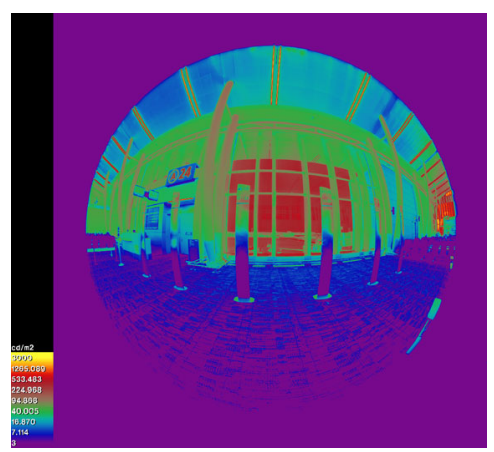

DGP: 0.09

When asked to self-report their comfort with the daylight, respondents in the gates with electrochromic glass reported greater daylight comfort than respondents in the gates with conventional window glass (Mann-Whitney U Test, $\mathrm{W}=45,378, \mathrm{r}=1.8 \mathrm{E}-05, \mathrm{p}=0.002$ : see Figure 4). 
Figure 4 Effects of window glass type on reported daylight comfort

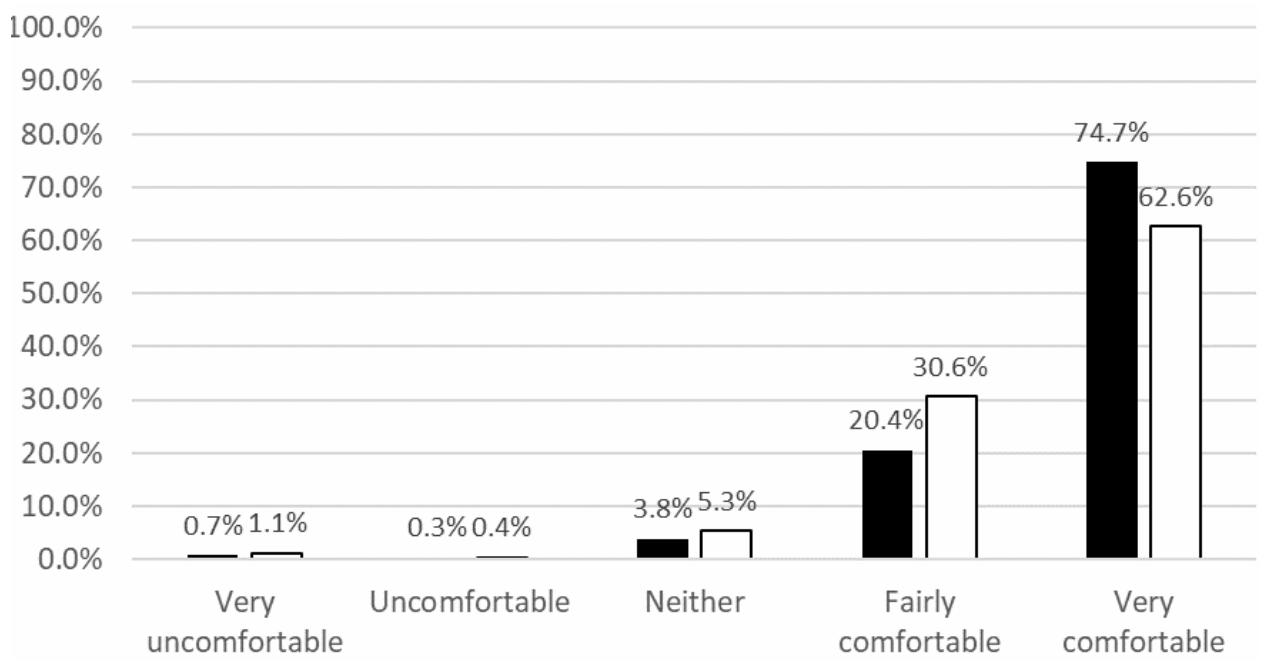

- Electrochromic $\square$ Control

\subsection{Visual environment for reading and screen use}

Respondents in the gates with electrochromic glass reported greater comfort with reading a book or magazine at their seat (Mann-Whitney U Test, $\mathrm{W}=47,229, \mathrm{r}=4.9 \mathrm{E}-05$, $\mathrm{p}=0.0001$ : see Figure 5) and using a laptop, tablet or cellphone at their seat (MannWhitney $\mathrm{U}$ Test, $\mathrm{W}=46,310, \mathrm{r}=1.4 \mathrm{E}-05, \mathrm{p}=0.004$ : see Figure 6) compared to respondents in the gates with conventional window glass.

Figure 5 Window glass effects on comfort with reading a book or magazine at their seat

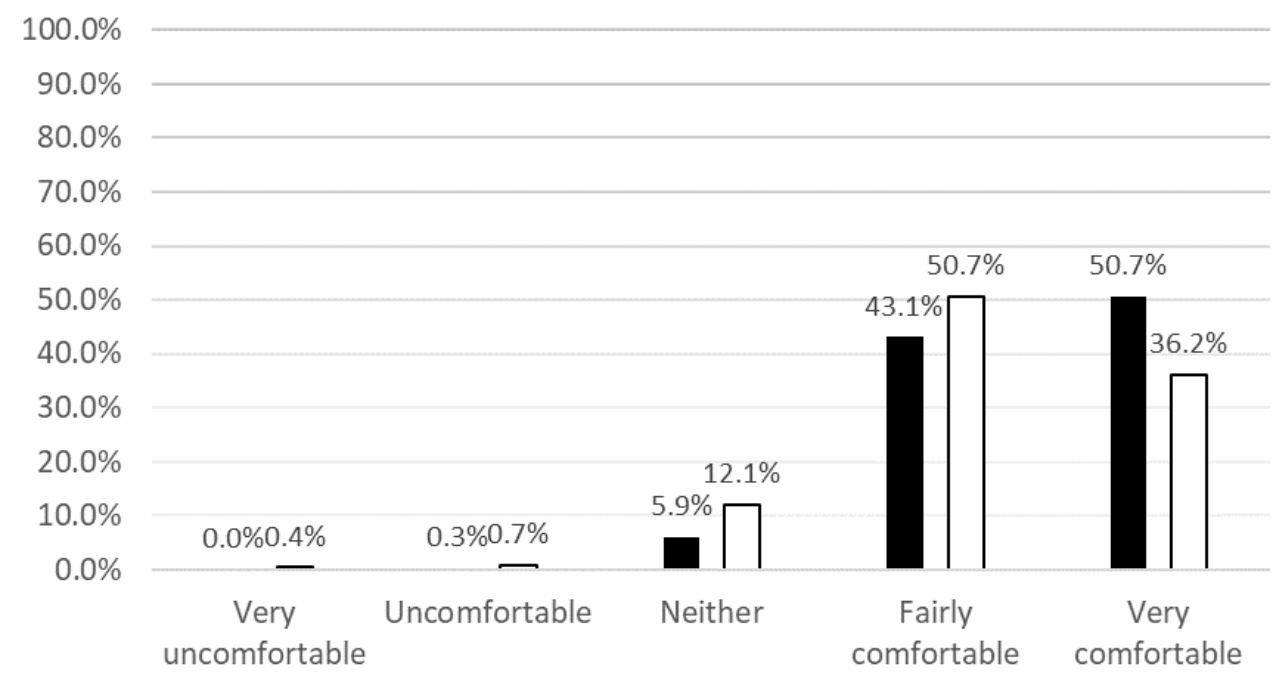

- Electrochromic aControl 
Figure 6 Window glass effects on comfort with using a laptop, tablet or cellphone at their seat

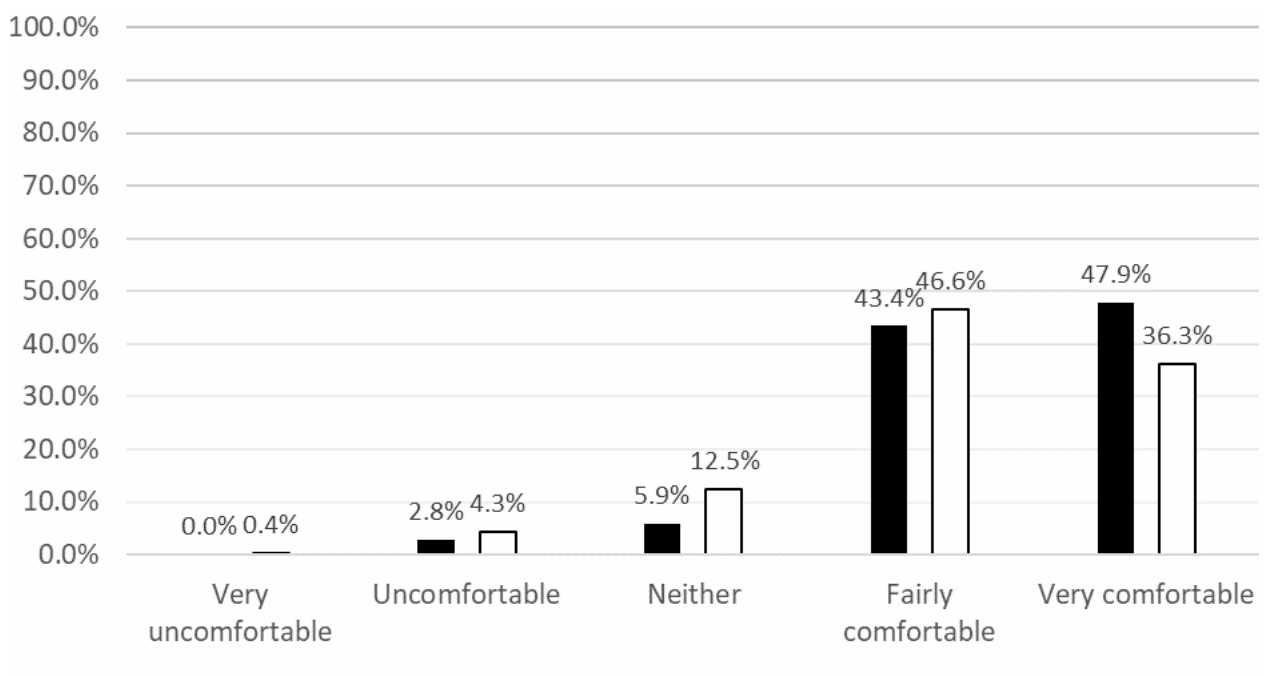

Electrochromic $\square$ Control

\subsection{Satisfaction with their experiences at the gate}

When asked about their overall experiences at the gate, respondents in the gates with electrochromic glass responded more favourably than respondents in the gates with conventional window glass (Mann-Whitney U Test, $\mathrm{W}=50,520, \mathrm{r}=2.07 \mathrm{E}-07, \mathrm{p}<0.001$ : see Figure 7). When quantified on a 1 to 5 scale from very unsatisfied to very satisfied, the mean satisfaction score was 4.41 in the concourse with electrochromic glass and 4.05 in the concourse with low-e glass. Participants were $68 \%$ more likely to be very satisfied with their gate experience when in the concourse with electrochromic windows.

Figure 7 Window glass effects on overall satisfaction at the gate

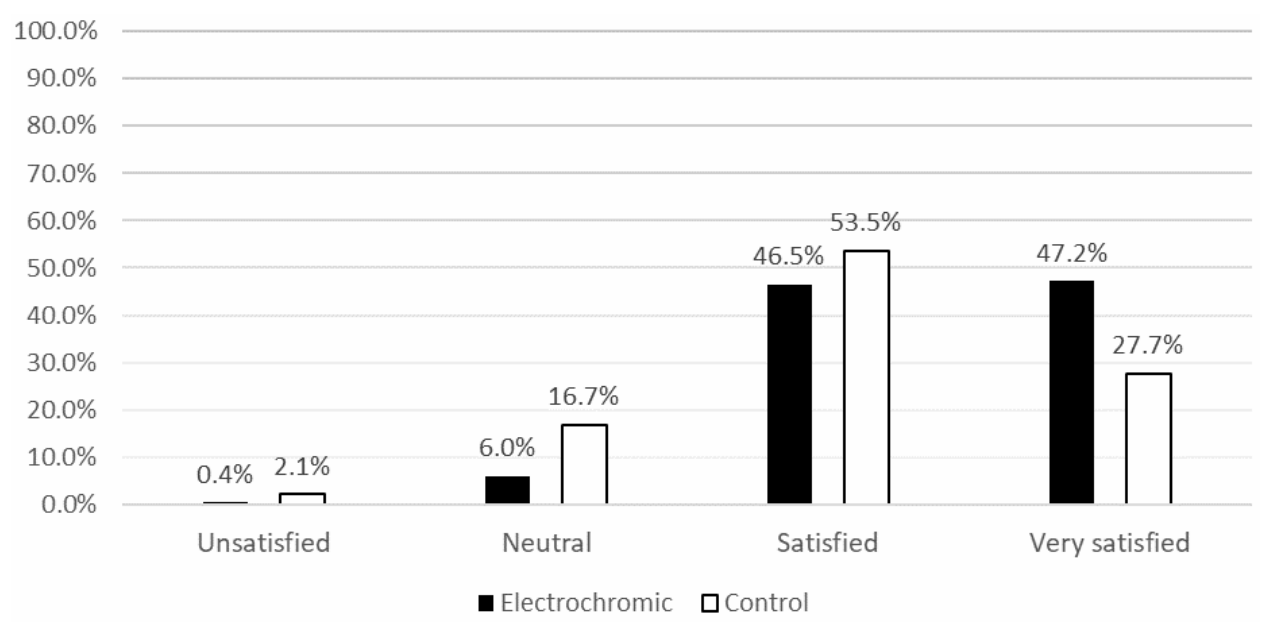




\subsection{Effects of light quality on positive mood and experiences}

When asked to rate their experience at the gate for a number of positive descriptors relating to their mood, emotions, and perceptions of the physical space on a scale of 1 to 7, passengers in the concourse with the electrochromic glass gave significantly higher ratings for each of the positive descriptors compared to those in the concourse with the conventional glass (see Figure 8).

Figure 8 Window glass effects on light quality on positive mood and experiences at the gate

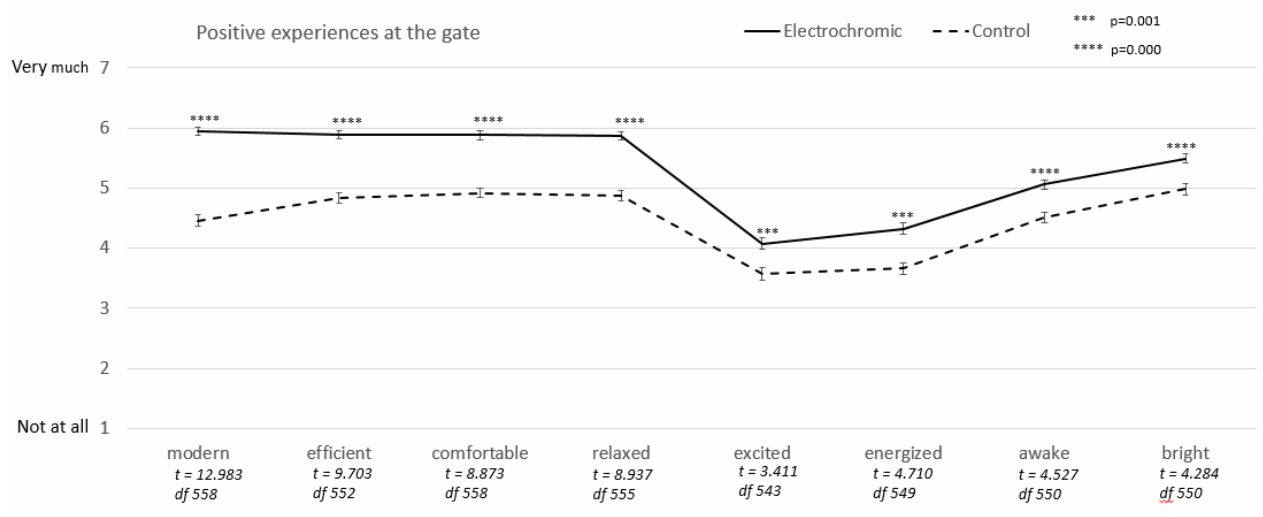

\subsection{Effects of light quality on negative mood and experiences}

Conversely, when asked to rate their experience at the gate for a number of negative emotional and perception descriptors, passengers in the concourse with the electrochromic glass reported significantly lower ratings for each of the negative descriptors compared to passengers in the concourse with the conventional glass (see Figure 9).

Figure 9 Window glass effects on light quality on negative mood and experiences at the gate

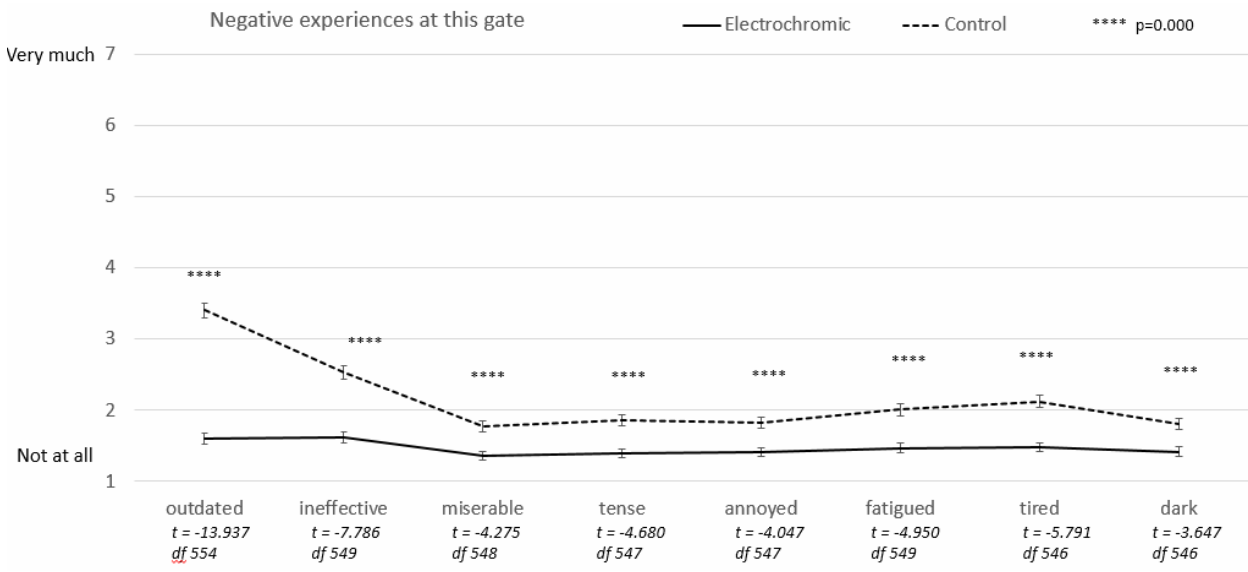




\subsection{Relationship between daylight comfort, perception of modernity and gate satisfaction}

Regardless of which concourse they were in, passengers reported higher gate satisfaction when they were more comfortable with daylight at the gate. Figure 10 shows the linear relationship between higher daylight comfort and higher gate satisfaction, each scored as a 1 to 5 scale from very unsatisfied to very satisfied.

Figure 10 Relationship between daylight comfort and gate satisfaction

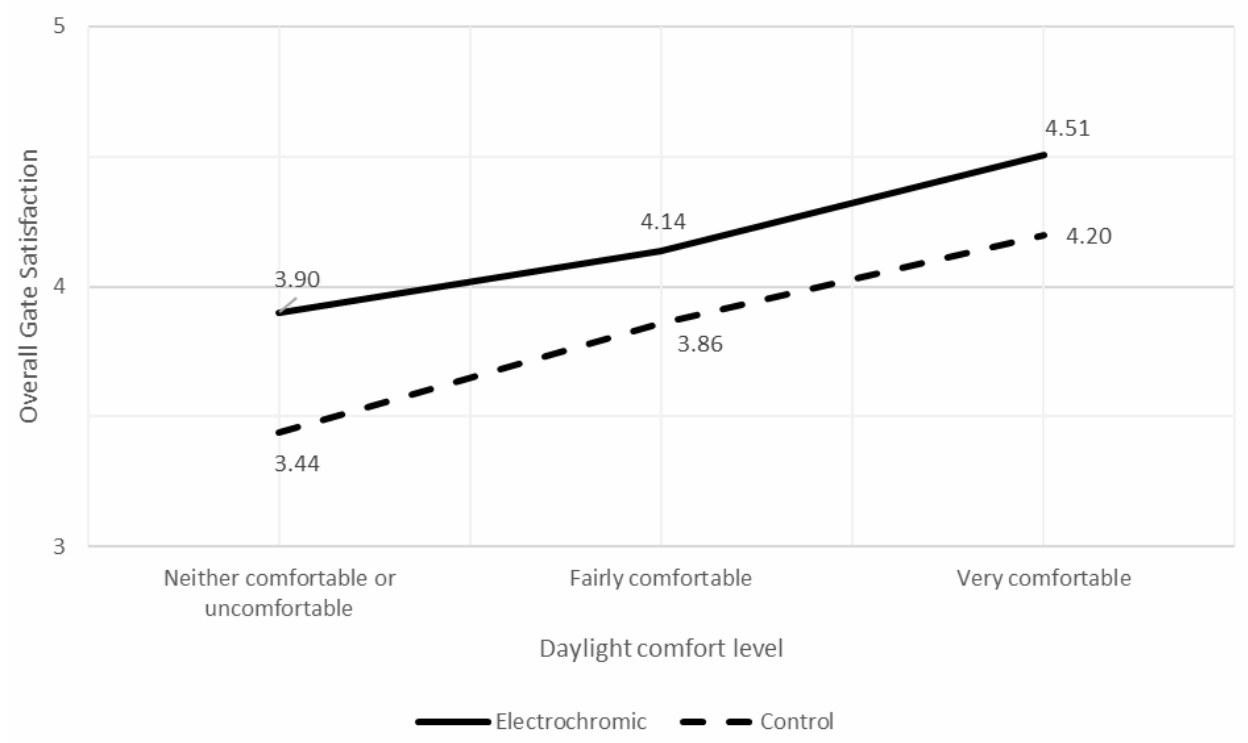

To account for several differentiating factors across the concourses that could influence gate satisfaction, including higher ceilings, wider corridors, larger gate areas and a more modern design in Concourse A expansion, a generalised linear model was used to control for confounding factors. Participants' responses on the level of modernity in the concourse served as a proxy for how modern features in the newly constructed concourse influenced their gate satisfaction. Table 3 shows how the effect of the concourse on gate satisfaction is explained through stepwise introduction of explanatory variables. With the introduction of both daylight comfort and modernity, the odds ratio for concourse approaches 1, indicating that gate satisfaction is fully explained by a combination of daylight comfort and modernity. Daylight comfort alone reduces the odds ratio of the concourse from 2.43 to 2.22 , and adding modernity lowers it further to 1.09. As a result, $15.7 \%$ of the concourse effect on gate satisfaction can be attributed to self-reported daylight comfort and the remaining $84.3 \%$ to their perception of modernity. Participants were 3.3 times more likely to report being very satisfied with the gate experience if they were very comfortable with the daylight comfort, after controlling for modernity $(\mathrm{p}<0.001)$. 
Table 3 Generalised linear models of gate satisfaction as a function of concourse, daylight comfort and perception of modernity

\begin{tabular}{lccc}
\hline Parameter & Estimate & Odds ratio & -value \\
\hline \multicolumn{4}{c}{ Gate satisfaction $\sim$ concourse } \\
\hline Intercept & -0.98 & - & $<0.001$ \\
Concourse A & 0.89 & 2.43 & $<0.001$ \\
\hline \multicolumn{4}{c}{ Gate satisfaction $\sim$ daylight comfort + concourse } \\
\hline Intercept & -1.96 & - & $<0.001$ \\
Very comfortable & 1.40 & 4.07 & $<0.001$ \\
Concourse A & 0.79 & 2.22 & $<0.001$ \\
\hline \multicolumn{4}{c}{ Gate satisfaction $\sim$ daylight comfort + modernity + concourse } \\
\hline Intercept & -4.51 & - & $<0.001$ \\
Very comfortable & 1.19 & 3.30 & $<0.001$ \\
Modernity & 0.57 & 1.76 & $<0.001$ \\
Concourse A & 0.08 & 1.09 & 0.691 \\
\hline
\end{tabular}

\section{Discussion}

Previous research has demonstrated the benefits of electrochromic glass on the visual experiences of passengers at their gates in an airport (Sibilio et al., 2016), and more generally, the benefits of optimal light and temperature conditions on passenger comfort, satisfaction, and retail revenue (Van Oel and van den Berkhof, 2013; Geng et al., 2017; Hedge et al., 2018; Kotopouleas and Nikolopoulou, 2018). The present field study adds to the research examining the effects of electrochromic glass by studying passenger experience in a concourse with electrochromic glass compared with a concourse with low-e glass in the same airport and over the course of the same days.

The results confirm previous research, finding that passengers at gates in the concourse with electrochromic glass had a significantly more comfortable visual experience, as indicated by both measured DGP and self-reported daylight comfort (Hedge et al., 2018). Passengers in the concourse with electrochromic glass reported significantly higher comfort with using both digital and paper media. The results demonstrated that daylight comfort was a driver of satisfaction; no matter which concourse they were in, comfort with the daylight conditions was significantly associated with higher overall gate satisfaction. Passengers were $68 \%$ more likely to be very satisfied with their gate experience in the concourse with electrochromic glass than those in the concourse with traditional low-e glass. Passengers in the new concourse said that it looked more modern, efficient and bright, and they said that they felt significantly more comfortable, awake, excited, relaxed, and energised by these conditions. By comparison, the conventional concourse passengers said that it felt dark, ineffective and outdated, and they reported feeling more tired, tense, annoyed, fatigued and miserable. These findings align closely with previous research of electrochromic glass in an office setting which found higher positive responses and lower negative responses on a similar Kansei scale (Choi et al., 2019). 
In addition to the benefits to lighting and views, electrochromic glass also reduces solar heat gain, which translate into cooler gate temperatures, as well as lower cooling costs that further reduce the airport's energy footprint. In the present study, gate temperatures were 9 degrees Celsius cooler in the concourse with electrochromic glass, which aligns closely with previous investigations of thermal conditions in airports with electrochromic glass (Hedge et al., 2018). Differences in thermal comfort could also influence gate satisfaction given the previous research indicating the dominant preference for cooler temperatures among passengers (Adey, 2008). The combined impact of improved lighting and thermal conditions from electrochromic glass has implications not just for passenger experience, but also physical health, sleep and cognitive function (Hedge and Nou, 2018; Boubekri et al., 2020).

The use of electrochromic glass was not the only difference between the two concourses. Concourse A expansion was recently completed and had more modern amenities including higher ceilings, larger gate areas and a greater window area. Some of the impact on gate satisfaction could be caused by these other factors. The relationship between daylight comfort and gate satisfaction, regardless of which concourse the passengers were in, helped determine the extent to which gate satisfaction was attributable to daylighting conditions. In addition, the survey responses at Gate A22, a low ceiling gate with a similar architecture and configuration as the gates in Concourse E, were comparable to the responses at the other Concourse A Expansion gates. Models including both daylight comfort and the perception of modernity suggest that $16 \%$ of the differences in gate satisfaction can be attributed to daylight as opposed to the other features that were different between the concourses.

While it is possible that improvements in daylight comfort could have been a result of the larger window size at Gates A24 and A26 rather the glazing material, increasing the size of the windows can lead to both positive and negative impacts on daylight comfort. Large glazed facades allow for greater daylight availability and expansive views, but also dramatically increase the potential for glare. Daylight penetration was about five times deeper in Concourse A Expansion than Concourse E. During the study period when the sun was at its zenith, daylight penetration was only about two feet in Concourse E compared to ten feet in Concourse A Expansion. Because the glass in Concourse A Expansion tinted in response to daylight conditions, glare reports were less frequent despite the significantly larger window area and greater daylight penetration.

Although the methodology used in this study balanced the sample sizes and characteristics between the two concourses, as with any field research it was not possible to control all extraneous variables. Participation was voluntary, and it is possible that there was selection bias based on which passengers chose to participate. It was not possible to take light measurements as passengers completed the computer-administered questionnaire, nor was it possible to measure incidences of glare for individual passengers.

Notwithstanding these study limitations, the consistency with research conducted at different airports (Korpela et al., 2015) and the analysis controlling for other factor that could influence gate satisfaction suggests that the benefits for passenger experiences that were found result in part from improved lighting conditions provided by the electrochromic glass. 


\section{References}

Adey, P. (2008) 'Airports, mobility and the calculative architecture of affective control', Geoforum, Vol. 39, No. 1, pp.438-451.

Boubekri, M., Lee, J., MacNaughton, P., Woo, M., Schuyler, L., Tinianov, B. and Satish, U. (2020) 'The impact of optimized daylight and views on the sleep duration and cognitive performance of office workers', International Journal of Environmental Research and Public Health, Vol. 17, No. 9, p.3219.

Choi, J., Loftness, V., Nou, D., Tinianov, B. and Yeom, D. (2019) 'Multi-season assessment of occupant responses to manual shading and dynamic glass in a workplace environment', Energies, Vol. 13, Article No. 60.

Geng, Y., Yu, J., Lin, B., Wang, Z. and Huang, Y. (2017) 'Impact of individual IEQ factors on passengers' overall satisfaction in Chinese airport terminals', Building and Environment, Vol. 112, No. 1, pp.241-249.

Hedge, A. and Nou, D. (2018) 'Effects of electrochromic glass on computer vision syndrome', Proceedings of the Human Factors and Ergonomics Society, Vol. 62, No. 1, pp.378-382.

Hedge, A., Nou, D. and Horton, R. (2018) 'Electrochromic glass enhances the passenger experience in airports', Ergonomics International Journal, Vol. 2, No. 6, p.1-:000162.

Johnson, K. (2019) 'Charlotte's airport fares well in nationwide satisfaction ranking', Patch, 27 September [online] https://patch.com/north-carolina/charlotte/charlotte-s-airport-fares-wellnationwide-satisfaction-ranking (accessed 31 December 2019).

Korpela, K., De Bloom, J. and Kinnunen, U. (2015) 'From restorative environments to restoration in work', Intelligent Buildings International, Vol. 7, No. 4, pp.215-223.

Kotopouleas, A. and Nikolopoulou, M. (2018) 'Evaluation of comfort conditions in airport terminal buildings', Building and Environment, Vol. 130, pp.162-178.

Martin, J. (2019) 'Passenger traffic rises to record high at Charlotte Douglas International Airport in 2018', Charlotte Business Journal, 21 February [online] https://www.bizjournals.com/ charlotte/news/2019/02/21/passenger-traffic-rises-to-record-high-at.html (accessed 31 December 2019).

Nabers, M.S. (2019) 'Blog: US airports launching huge renovation projects', Airport World, 8 April [online] http://www.airport-world.com/news/general-news/7100-blog-us-airportslaunching-huge-renovation-projects.html (accessed 31 December 2019).

Power, J.D. (2019) North American Airports Struggle to Keep Travelers Happy Amid Construction Delays and Surging Passenger Volumes [online] https://www.jdpower.com/business/pressreleases/2019-north-america-airport-satisfaction-study (accessed 31 December 2019).

Sibilio, S., Rosat, A., Scorpio, M., Luliano, G., Ciamp, G., Vanoli, G.P. and de Rossi, F.A (2016) 'Review of electrochromic windows for residential applications', International Journal Heat \& Technology, Vol. 34, No. 2, pp.S481-S488.

United States Department of Transportation (USDOT) (2019) The Economic Impact of Civil Aviation on the U.S. Economy. Federal Aviation Administration, Office of Performance Analysis, Systems Operation Services, Air Traffic Organization [online] https://www.faa.gov/ air traffic/publications/media/2016-economic-impact-report FINAL.pdf (accessed 31 December 2019).

United States Department of Transportation (USDOT) (2020) Estimated June 2019 U.S. Airline Traffic Data, Bureau of Transportation Statistics [online] https://www.bts.gov/newsroom/ estimated-june-2019-us-airline-traffic-data (accessed 31 January 2020).

Van Oel, C.J. and van den Berkhof, F.W. (2013) 'Consumer preferences in the design of airport passenger areas', Journal of Environmental Psychology, Vol. 36, pp.280-290. 
Wienold, J. and Christoffersen, J. (2007) 'Evaluation methods and development of a new glare prediction model for daylight environments with the use of CCD cameras', Energy and Buildings, Vol. 38, No. 7, pp.743-757.

$\mathrm{Wu}, \mathrm{C}$. and Chen, Y. (2019) 'Effects of passenger characteristics and terminal layout on airport retail revenue: an agent-based simulation approach', Transportation Planning and Technology, Vol. 42, No. 2, pp.167-186. 